Cahiers $d u$ MONDE RUSSE

\section{Cahiers du monde russe}

Russie - Empire russe - Union soviétique et États indépendants

$45 / 3-4 \mid 2004$

Varia

\title{
Francine-Dominique Liechtenhan, Les trois christianismes et la Russie
}

\section{Aleksandr Lavrov}

\section{OpenEdition}

\section{Journals}

Édition électronique

URL : https://journals.openedition.org/monderusse/4172

DOI : 10.4000/monderusse.4172

ISSN : $1777-5388$

Éditeur

Éditions de l'EHESS

\section{Édition imprimée}

Date de publication : 1 juillet 2004

Pagination : 627-624

ISBN : 2-7132-2009-2

ISSN : $1252-6576$

Référence électronique

Aleksandr Lavrov, «Francine-Dominique Liechtenhan, Les trois christianismes et la Russie », Cahiers du monde russe [En ligne], 45/3-4 | 2004, mis en ligne le 16 juin 2009, consulté le 02 septembre 2022 URL : http://journals.openedition.org/monderusse/4172; DOI : https://doi.org/10.4000/monderusse. 4172

Ce document a été généré automatiquement le 2 septembre 2022.

Tous droits réservés 


\title{
Francine-Dominique Liechtenhan, Les trois christianismes et la Russie
}

\author{
Aleksandr Lavrov
}

\section{RÉFÉRENCE}

Francine-Dominique LIECHTENHAN, Les trois christianismes et la Russie. Les

voyageurs occidentaux face à l'Église orthodoxe russe, $\mathrm{XV}^{\mathrm{e}}-\mathrm{xVIII}{ }^{\mathrm{e}}$ siècle. Paris, CNRS

Éditions, 2002, 208 p.

Le livre de Francine-Dominique Liechtenhan est consacré au rôle de la chrétienté orthodoxe et de l'Église russe dans l'image de la Russie véhiculée par les voyageurs occidentaux à l'époque moderne. Cette image a fait l'objet de plusieurs études à partir des années 1950. Depuis les travaux de Karl-Heinz Ruffmann (1952) et Andreas Kappeler (1972) jusqu'au livre de Jean-Claude Roberti et Michel Mervaud (1991), une distinction était opérée entre l'image « anglaise », « allemande » (ou plutôt l'image présentée par les publications germanophones de l'époque) et "française » ${ }^{1}$. À l'opposé, l'ouvrage récent de Stéphane Mund tente de prouver l'existence d'une image commune de la Moscovie au Xvie siècle qui serait propre à toute l'Europe occidentale ${ }^{2}$. Sans prendre position directement dans cette discussion, F.-D. Liechtenhan montre son orientation de manière implicite en soulignant l'influence très forte de l'identité confessionnelle des observateurs, qui marquait leur image de la Moscovie. Si je comprends bien la thèse principale du livre, il s'agit de la coexistence de ces images " confessionnelles ", c'est-àdire de l'image catholique et des images protestantes, jusqu'à la fin du siècle des Lumières.

Cette thèse est développée dans le livre d'une manière claire et logique. Tout d'abord, après l'échec des premières tentatives de conversion des Mongols, le Saint-Siège constate la dévastation de la Russie et se demande si l'union avec les Russes - et la réunion de ceux-ci avec l'Église romaine catholique - est possible (p. 17). Une tout autre perspective s'ouvre au commencement du xvie siècle. Selon l'historienne, "le 
rapprochement avec Moscou avait un double objectif » pour le Saint-Siège : « d'une part, créer un équilibre géographique par rapport à l'empereur d'Allemagne, Charles Quint, grand rival des papes. À partir des années 1520, il s'agissait, d'autre part, de contrer la Réforme" (p. 27). Des auteurs comme Johann Faber et Sigismund von Herberstein se demandaient si l'Église russe pouvait être considérée comme un contrepoids à la croissance rapide de la Réforme, ou si, au contraire, elle confirmait certaines prises de position protestantes (par exemple, à l'égard du mariage du clergé). L'historienne conclut que la perception de l'Église russe par les auteurs catholiques restait dépendante de la perspective d'union des Églises, ce qui explique qu'ils «ignoraient » parfois «le poids de l'histoire dans la mentalité des Slaves de l'Est [...], sous-estimaient leur héritage, leur trajectoire spécifique, leur conscience de représenter le seul pays orthodoxe libre » (p. 179).

Quant aux protestants, F.-D. Liechtenhan affirme que leurs critiques des rites de l'Église russe étaient souvent calquées sur leurs reproches à l'égard des rites catholiques. Par ailleurs, « ils ne se mêlèrent guère des affaires intérieures de leurs hôtes et surent, de ce fait, se ménager une position privilégiée dans la société russe» (p.9), position qu'ils craignaient de perdre dans l'éventualité d'une union probable entre l'église russe et Rome. Or il me semble qu'entre la "position privilégiée " des protestants dans le «Faubourg allemand» de Moscou et les affirmations des voyageurs protestants, il n'y avait pas un lien aussi direct. Des voyageurs protestants comme Adam Olearius se demandaient si les Russes étaient vraiment des chrétiens, sans envisager comment de telles prises de position pouvaient influencer l'attitude des Moscovites à l'égard des protestants, ce qui offrit, dès le xvire siècle, à Juraj Križanič un prétexte pour affirmer que les auteurs protestants étaient bien plus négatifs à l'égard des Russes que les auteurs catholiques.

La réforme pétrovienne de l'Église, généralement approuvée par les observateurs étrangers, constitue un tournant décisif. Les voyageurs et les diplomates occidentaux sont également unanimes dans leur condamnation du clergé russe orthodoxe comme l'une des forces principales d'opposition à la transformation de la société russe voulue par Pierre le Grand. Même la fuite du tsarévitch leur semble être un résultat des " insinuations» du clergé russe, tandis que d'autres observateurs accusent le clergé d'avoir calomnié le malheureux Aleksej Petrovič (p. 118, 121). L'historienne montre très bien que si les auteurs catholiques s'étonnent en général de la radicalité des premières réformes de Pierre le Grand et des activités du "synode très-bouffon et très-pochard " (Johann Korb), les protestants se montrent à l'inverse des partisans résolus de la réforme pétrovienne de l'Église (comme Weber ou Vockerodt). Dans le cas particulier de Weber, Liechtenhan montre cependant que l'apologie du tsar-réformateur, telle qu'elle s'exprime dans ses ouvrages publiés, contraste avec les remarques pessimistes de sa correspondance diplomatique, qui n'était pas destinée à un large public.

Ces images « confessionnelles » de la Russie se dispersent pendant le siècle des Lumières, en laissant place à diverses interprétations du passé et de l'avenir de l'Église russe. Même le mythe de Pierre le Grand n'est plus intouchable. L'ambiguïté de la réforme pétrovienne devient évidente aux yeux du diplomate français Marie-Daniel de Corberon, selon lequel, « en muselant son clergé, Pierre avait privé le petit peuple de son seul moyen de formation » (p.160). La question de la tolérance, qui émerge sous Pierre le Grand et qui fut d'abord jugée de façon positive, devint de plus en plus la cible des critiques. Même la perception des activités missionnaires de l'Église russe change 
radicalement. Si Philippe Avril reprochait en 1692 à l'Église russe de tolérer des païens au centre du pays sans essayer de les convertir, près d'un siècle plus tard, des auteurs comme le Hollandais Van Woenzel (1783) et le Français Nicolas Chantreau (1794) condamnent le clergé russe pour son intolérance à l'égard des vieux-croyants et des Juifs.

Le seul reproche que l'on pourrait faire à l'ouvrage est sa structure chronologique, bien adaptée à la présentation de certains sujets (par exemple, les relations de la Russie avec le Saint-Siège), mais plus contestable pour le traitement d'autres thèmes importants (comme le schisme des vieux-croyants ou l'eschatologie orthodoxe).

Par ailleurs, l'historienne remarque avec raison que « la fin tragique d'Avvakoum n'attira pas " l'attention des voyageurs étrangers (p. 74 et 95), et plus loin elle note que «les persécutions des vieux-croyants furent passées sous silence » (p. 76). Mais ce silence, et le fait que les voyageurs étrangers ignoraient un point essentiel de l'histoire religieuse russe du xviIe siècle, ne justifient-ils pas l'ancienne méfiance des historiens russes, comme Ključevskij et Seredonin, qui répugnaient à utiliser des récits des voyageurs occidentaux comme source pour l'histoire religieuse? On peut regretter que F.D. Liechtenhan, lorsqu'elle fait une trouvaille précieuse, au lieu de l'approfondir, se précipite en avant, laissant à ses lecteurs le soin de l'apprécier et de l'étudier. Par exemple, elle reproduit l'information du Saxe Laurent Rinhuber, suivant laquelle « pour les Russes, le pape représentait simplement l'Antéchrist» (p. 84). Or c'est cette information qui nous permet de mesurer la réception par la société russe de textes comme « Le livre de Saint Cyrille » ou le « Livre de la Foi ».

Mais ces remarques ne diminuent pas la valeur exceptionnelle du livre, qui est le résultat d'une lecture frontale des sources - latines, allemandes, françaises, italiennes et anglaises - toutes lues en langue originale. La bibliographie est très complète. Dans la liste des sources secondaires, il faut noter néanmoins l'absence de l'ouvrage important de Gabriele Scheidegger, ainsi que des articles de Frank Kämpfer et de Anna L. Horoškevič, consacrés à l'image de l'Église russe chez Sigismund von Herberstein ${ }^{3}$.

\section{NOTES}

1. K.-H. Ruffmann, Das Rußlandbild im England Shakespeares, Göttingen, Musterschmidt Wissenschaftl. Verlag, 1952 ; A. Kappeler, Ivan Groznyj im Spiegel der ausländischen Druckschriften seiner Zeit, Berne, H. Lang, 1972 ; M. Mervaud, J.-C. Roberti, Une infinie brutalité. L'image de la Russie dans la France des XVI $I^{e}$ et XVII siècles, Paris, Institut des Études slaves, 1991.

2. S. Mund, Orbis Russiarum : genèse et développement de la représentation du monde "russe " en Occident à la Renaissance, Genève, Droz, 2003, 598 p. [Cet ouvrage fait l'objet d'une recension dans ce numéro, p. 617-619].

3. G. Scheidegger, Perverses Abendland - barbarisches Russland. Begegnungen des 16. und 17. Jahrhunderts im Schatten kultureller Missverständnisse, Zurich, 1993 ; F. Kämpfer, "Siegmund von Herbersteins "Rerum Moscoviticarum Commentarii" als religionsgeschichtliche Quelle », in Siegmund von Herberstein : Kaiserliche Gesandte und Begründer der Russlandskunde und die europäische Diplomatie, Graz, 1989 ; A. L. Horoškevič, "Cerkov' i gosudarstvo v “Zapiskah o Moskovii” Sigizmunda Gerberštejna », in Cerkov', obščestvo i gosudarstvo v feodal'noj Rossii, Moscou, 1990. 